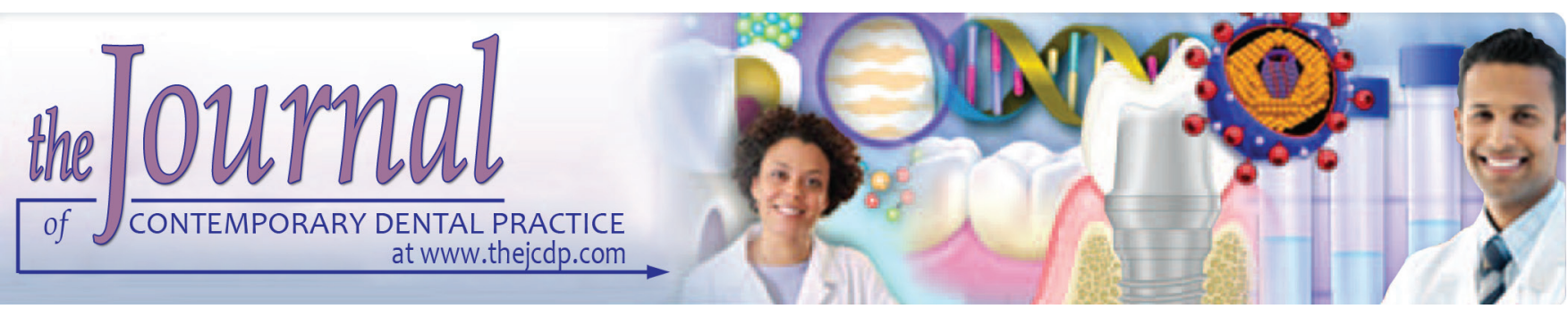

\title{
Knowledge, Attitude, and Behavior toward Evidence-based Dentistry among Dental Professionals in Jodhpur, Rajasthan, India
}

${ }^{1}$ Parul Rawat, ${ }^{2}$ Rahul P Goswami, ${ }^{3}$ Gagandeep Kaur, ${ }^{4}$ Tarun Vyas, ${ }^{5}$ Neha Sharma, ${ }^{6}$ Abhinav Singh

\begin{abstract}
Introduction: Rendering quality care to the patient, dentists needs to update their skills and knowledge with latest diagnostics and treatment modalities. Evidence-based dentistry can provide best-known treatments.
\end{abstract}

Aim: To assess knowledge, attitude, and practice of oral healthcare professionals toward evidence-based dentistry among dental professionals.

Materials and methods: A cross-sectional study was conducted for a period of 3 months from April 2017 to June 2017 in Jodhpur city, Rajasthan, India. The data were collected by using closedended questionnaires. A total of 240 study subjects participated in the survey, which include dental practitioners and dentists attached to the two private dental colleges in the Jodhpur. Chisquare test was used to determine significant difference among the three groups.

Results: Statistically significant difference among the three groups (academicians, practitioners, and academicians into dental practice) was found with regard to awareness of dentists

\footnotetext{
${ }^{1}$ Department of Pedodontics and Preventive Dentistry, Pacific Dental College \& Hospital, Udaipur, Rajasthan, India

${ }^{2}$ Department of Dentistry, Jawaharlal Nehru Medical College Ajmer, Rajasthan, India

${ }^{3}$ Department of Pedodontics and Preventive Dentistry, College of Dental Sciences, Amargadh, Gujarat, India

${ }^{4}$ Department of Oral Medicine and Radiology, R.R. Dental College \& Hospital, Udaipur, Rajasthan, India

${ }^{5}$ Department of Conservative Dentistry and Endodontics, Kalka Dental College \& Hospital, Meerut, Uttar Pradesh, India

${ }^{6}$ Department of Orthodontics and Dentofacial Orthopedics Divya Jyoti College of Dental Sciences \& Research, Modinagar Uttar Pradesh, India

Corresponding Author: Rahul P Goswami, Department of Dentistry, Jawaharlal Nehru Medical College, Ajmer, Rajasthan India, Phone: +91941374320, e-mail: dr.rahul1985@gmail.com
}

about extracting journals, review publications, and databases relevant in carrying out evidence-based practice (EBP); $72.4 \%$ of academician felt lack of personal time was one of the major perceived barriers and about $50.7 \%$ of academician believe that learning skills of evidence-based dentistry helps them to utilize evidence-based dentistry in daily practice.

Conclusion: Majority of the oral health practitioners were not aware about the concept of evidence-based dentistry. The regulatory body of dental sciences in India should make some necessary changes in the dental curriculum to include the concept of evidence-based dentistry in detail.

Clinical significance: To improve the clinical expertise of the dental professional, to aid dental professional to reach best decision regarding dental treatment of the patient, to improve patient safety, and to improve the success rate of dental treatments, evidence-based dentistry should be the integral part of everyday dental practice.

Keywords: Dentists, Evidence-based dentistry, Knowledge.

How to cite this article: Rawat P, Goswami RP, Kaur G, Vyas T, Sharma N, Singh A. Knowledge, Attitude, and Behavior toward Evidence-based Dentistry among Dental Professionals in Jodhpur, Rajasthan, India. J Contemp Dent Pract 2018;19(9):1140-1146.

Source of support: Nil

Conflict of interest: None

\section{INTRODUCTION}

It is an old saying that in the medical or dental field, more the experience of a physician or a dentist, better the quality of care provided, but in reality, there is an inverse relationship between years of practice and the quality of health care provided. ${ }^{1}$ In the healthcare sector, satisfaction of the patient is the prime motto and dentistry is no exception. ${ }^{2}$ Utmost requirement for the dental professional to render quality care to the patient is to update their knowledge and skills with latest diagnostics and treatment modalities. Dental professionals may find large number 
of new products and different treatment modalities of various dental diseases available in the market; hence, it becomes highly impossible for any dental practitioner to be aware and keep track of all the updates. Therefore, different ways have been suggested to be updated, one of which is EBP. ${ }^{3}$

Evidence-based dentistry is not a new concept in the medical and dental field; even though it is accepted worldwide, its applicability in the dental and medical field is still in the nascent stage. ${ }^{4}$ The EBP is considered to be the best possible approach available to provide interventions and the benefits of EBP were known to be efficient, safe, and cost-effective. ${ }^{5,6}$

David Sackett was the initiator of EBP by defining it as "integrating individual clinical expertise with the best available external clinical evidence from systemic research. ${ }^{\prime 7}$ The dental practitioner should refer the scientific literature and especially meta-analysis or systematic review done on particular topics dealing with recent advances and success rates of various treatment modalities to solve the problem based on clinical question.

Nowadays, the practice of dentistry has changed a lot as in the medical field, and this is mainly due to information available on the internet and the consumer movement, and even the relationship between the clinician and patient has changed. Now the patient has become a partner in decision-making which has been mediated by internet advancement, whereas previously popular sources of information were textbooks, senior dentists, and colleagues; but methods of collecting information has changed over the period of time because of interactive learning through computer- and web-based courses. Best-known treatment can be provided to the patient by seeking the evidence-based dentistry. ${ }^{8,9}$

The concept of evidence-based dentistry is not new in Indian scenario, but still the acceptability of the proved better treatment modalities by the dental professionals is in the infancy stage. There are very few studies in the literature which assessed knowledge and attitude of dental practitioners toward evidence-based dentistry. Shaw reported on the Cochrane collaboration that in spite of good amount of evidence available for a particular therapy or intervention, it takes many years in to general use. ${ }^{10}$ Although efforts have been taken in India to broaden the knowledge of dental practitioners toward EBP throughout the country, still there is dearth of information regarding the same and hence, the present study was undertaken to assess knowledge, attitude, and practice of oral healthcare professionals toward evidence-based dentistry.

\section{MATERIALS AND METHODS}

A cross-sectional study was conducted to assess knowledge, attitude, and practice of oral healthcare professionals toward evidence-based dentistry for a period of 3 months from April 2017 to June 2017 in Jodhpur, Rajasthan, India.

Ethical approval was taken from the ethical clearance committee of Pacific Dental College \& Hospital. Principals of the two dental colleges were contacted and permission was taken to conduct the study, and practitioners of the Jodhpur city were also contacted. The aim of the study was clearly explained to all the subjects and written informed consent was obtained. A total of 240 study subjects participated in the survey which includes dental practitioners and dentists attached to the two private dental colleges in the Jodhpur. Study subjects were divided into three groups —only academicians (group I), only dental practitioners (group II), and academicians with dental practitioners (group III).

The private dental practitioners as well as academicians and clinicians into practice working in both the private dental colleges were visited by a single examiner and all the available and willing subjects were given the questionnaire on the day of visit. The subjects were asked to respond to each item according to the response format provided in the questionnaire. The examiner was available throughout the filling of the questionnaire to explain the question and aim of the study to the participants.

A pilot study was carried out on 40 subjects before starting the main study to check the feasibility of the study. Validity and reliability of the questionnaire were confirmed by using Cronbach's alpha (0.85) and split half reliability $(0.78)$ respectively.

Data were collected by using close-ended questionnaires. The original questionnaire was prepared by referring the study of Kumar et al. ${ }^{11}$ It included questions on demographic details, three questions to check awareness on Cochrane Database of Systematic Reviews, evidence-based dentistry and database of abstracts and systematic reviews, 10 questions on understanding of technical words like relative risks, meta-analysis, publication bias, class interval, and five questions to find out perceived barriers related to EBP, which include questions related to lack of personal time, context of primary care, attitudes of patients, and personal attitude. List of all the practicing dentists within Jodhpur city and in and around was obtained from the administrative wing of the Indian Dental Association of Jodhpur Branch. There were 350 registered dentists, hence, 350 sets of questionnaire were personally disturbed to each participant. Incomplete questionnaire and the persons who were not willing to fill the questionnaire were excluded from the study. Only 240 questionnaires were returned, therefore, making a response rate of $69 \%$.

Microsoft excel sheet and a coding system were used for the data entry. In statistical analysis, the data were analyzed using Statistical Package for the Social Sciences 
(SPSS) version 16.0 (IBM SPSS Inc., Chicago, Illinois, USA). Chi-square test and analysis of variance test were used to find statistical differences among demographic variables and among three groups (academicians, practitioners, and academicians into dental practice).

\section{RESULTS}

It was found that among all the three groups, male participants were more as compared with the females. Based on membership of research gate, $74.6 \%$ of dentists belong to group I; $71.4 \%$ of dentists belong to group II; and $70 \%$ of dentists were in group III. It was noted that $69.5 \%$ in group I, $79.2 \%$ in group II, and $72 \%$ in group III were shown practice characteristics; dentists in group I were academicians so they did not do any intervention on patients and only examination was done. Similarly, $89.5 \%$ of dentists under group I and $75 \%$ of dentists under group II had their residence in urban areas, while
$56.7 \%$ of dentists under group III were located in rural setting (Table 1).

Overall, $62.08 \%$ of dentists under group were unaware about evidence-based dentistry with the lowest in group III (31.08\%) and highest among group I compared with $79.7 \%$. Similarly, $40.5 \%$ of group III dentists were aware, but have not used Cochrane Database of Systematic Reviews as compared with $7.24 \%$ of dentists in group I. It was also found that, overall, $12.5 \%$ of dentists agreed that database of abstracts and systematic reviews would not help in clinical decision-making with most agreed being group III dentists (28.37\%) and least among dentists in group I (8.69\%). Statistically significant difference among the three groups was found with regard to awareness of dentists about extracting journals, review publications, and databases relevant in carrying out EBP (Table 2).

It was noted that $41.89 \%$ of group III dentists had some understanding about systematic reviews. Overall,

Table 1: Demographic and practice-based variables

\begin{tabular}{|c|c|c|c|c|c|c|}
\hline Variables & & $\begin{array}{l}\text { Group I }(n=138 \\
100 \%)\end{array}$ & $\begin{array}{l}\text { Group II }(n=28 \\
100 \%)\end{array}$ & $\begin{array}{l}\text { Group III } \\
(n=74 ; 100 \%)\end{array}$ & $\begin{array}{l}\text { Total }(n=240 ; \\
100 \%)\end{array}$ & $p$-value \\
\hline \multirow[t]{2}{*}{ Gender } & Male & $77(55.79)$ & $16(57.14)$ & $49(66.21)$ & $142(59.16)$ & $0.03^{*}$ \\
\hline & Female & $61(44.20)$ & $12(42.85)$ & $25(33.78)$ & $98(40.83)$ & \\
\hline \multirow[t]{4}{*}{ Age group (years) } & $22-30$ & $33(23.91)$ & $4(14.28)$ & $19(25.67)$ & $56(23.33)$ & $0.01^{*}$ \\
\hline & $31-40$ & $42(30.43)$ & $9(32.14)$ & $21(28.37)$ & $72(30.0)$ & \\
\hline & $41-50$ & $36(26.08)$ & $11(39.28)$ & $26(35.13)$ & $73(30.41)$ & \\
\hline & 50 and above & $27(19.56)$ & $4(14.28)$ & $8(10.81)$ & $39(16.25)$ & \\
\hline \multirow[t]{2}{*}{ Member of research gate } & Yes & $103(74.63)$ & $20(71.42)$ & $52(70.27)$ & $175(72.91)$ & $0.01^{*}$ \\
\hline & No & $35(25.36)$ & $8(28.57)$ & $22(29.79)$ & $65(27.08)$ & \\
\hline \multirow{2}{*}{$\begin{array}{l}\text { Practice size }<5000 \text { patients/ } \\
\text { years }\end{array}$} & Yes & $96(69.56)$ & $18(64.28)$ & $59(79.72)$ & $173(72.08)$ & $0.026^{*}$ \\
\hline & No & $42(30.43)$ & $10(35.71)$ & $15(20.27)$ & $67(27.61)$ & \\
\hline \multirow[t]{3}{*}{ Settings } & Urban & $124(89.55)$ & $21(75.0)$ & $32(43.24)$ & $177(73.75)$ & $0.01^{*}$ \\
\hline & Rural & $14(10.14)$ & $7(25.0)$ & $42(56.75)$ & $63(26.25)$ & \\
\hline & No & $120(86.95)$ & $10(35.71)$ & $43(58.10)$ & $173(72.08)$ & \\
\hline
\end{tabular}

*Statistically significant at $p<0.05$

Table 2: Awareness of dentists about extracting journals, review publications, and databases relevant in carrying out EBP

\begin{tabular}{|c|c|c|c|c|c|c|}
\hline $\begin{array}{l}\text { Awareness of } \\
\text { dentist }\end{array}$ & & $\begin{array}{l}\text { Group I }(n=138 \\
100 \%)\end{array}$ & $\begin{array}{l}\text { Group II }(n=28 ; \\
100 \%)\end{array}$ & $\begin{array}{l}\text { Group III }(n=74 ; \\
100 \%)\end{array}$ & $\begin{array}{l}\text { Total }(n=240 \\
100 \%)\end{array}$ & $p$-value \\
\hline \multirow{3}{*}{$\begin{array}{l}\text { Evidence-based } \\
\text { dentistry }\end{array}$} & Unaware & $110(79.71)$ & $16(57.14)$ & $23(31.08)$ & $149(62.08)$ & \multirow[t]{3}{*}{$0.001^{*}$} \\
\hline & Aware but did not use & $18(13.04)$ & $10(7.24)$ & $41(55.40)$ & $69(28.25)$ & \\
\hline & $\begin{array}{l}\text { Unable to help in clinical } \\
\text { decision-making }\end{array}$ & $10(7.24)$ & $2(7.14)$ & $10(13.51)$ & $22(9.1)$ & \\
\hline \multirow{4}{*}{$\begin{array}{l}\text { Cochrane } \\
\text { Database of } \\
\text { Systematic } \\
\text { Reviews }\end{array}$} & Unaware & $100(72.46)$ & $12(42.85)$ & $20(27.02)$ & $132(55.0)$ & \multirow[t]{4}{*}{$0.024^{*}$} \\
\hline & Aware but did not use & $10(7.24)$ & $4(14.28)$ & $30(40.54)$ & $44(18.33)$ & \\
\hline & Read & $18(13.04)$ & $7(25.0)$ & $12(16.21)$ & $37(15.41)$ & \\
\hline & $\begin{array}{l}\text { Unable to help in clinical } \\
\text { decision-making }\end{array}$ & $10(7.24)$ & $5(17.85)$ & $10(13.51)$ & $25(10.41)$ & \\
\hline \multirow{4}{*}{$\begin{array}{l}\text { Database of } \\
\text { abstracts and } \\
\text { systematic } \\
\text { reviews }\end{array}$} & Unaware & $90(43.47)$ & $8(28.51)$ & $24(32.43)$ & $122(50.82)$ & \multirow[t]{4}{*}{$0.037^{*}$} \\
\hline & Aware but did not use & $20(14.49)$ & $8(28.57)$ & $24(32.43)$ & $52(21.66)$ & \\
\hline & Read & $16(11.59)$ & $6(21.42)$ & $14(18.91)$ & $36(15.0)$ & \\
\hline & $\begin{array}{l}\text { Unable to help in clinical } \\
\text { decision-making }\end{array}$ & $12(8.69)$ & $6(21.42)$ & $12(28.37)$ & $30(12.5)$ & \\
\hline
\end{tabular}


$54 \%$ group III dentists felt that odds ratio would not be helpful for them to understand evidence-based dentistry, while $39.1 \%$ of dentists in group I felt that it is not helpful to understand clinical effectiveness and would not be helpful to understand evidence-based dentistry. Statistically significant difference was found among the three groups with respect to understanding of technical terms used in evidence-based dentistry (Table 3).
In group I, $72.4 \%$ of dentists felt that lack of personal time was one of the major barriers for practicing evidencebased dentistry. Overall, $24.16 \%$ of dentists felt that lack of personal initiative and organizational inertia were the barriers to practice evidence-based dentistry. A total of $48.6 \%$ of dentists under group III felt that lack of hard evidence and patients' expectation were considered the major perceived barriers for practicing evidence-based

Table 3: Understanding of technical terms used in evidence-based dentistry

\begin{tabular}{|c|c|c|c|c|c|c|}
\hline Technical terms & & $\begin{array}{l}\text { Group I } \\
(n=138 \\
100 \%)\end{array}$ & $\begin{array}{l}\text { Group II } \\
(n=28 ; \\
100 \%)\end{array}$ & $\begin{array}{l}\text { Group III } \\
(n=74 ; \\
100 \%)\end{array}$ & $\begin{array}{l}\text { Total } \\
(n=240 ; \\
100 \%)\end{array}$ & $p$-value \\
\hline \multirow[t]{4}{*}{ Relative risk } & It would not be helpful for me to understand & $40(28.98)$ & $7(25.0)$ & $20(27.02)$ & $67(27.91)$ & $0.043^{*}$ \\
\hline & Do not understand but would like to & $30(21.73)$ & $8(28.57)$ & $30(40.54)$ & $68(28.33)$ & \\
\hline & Some understanding & $34(24.63)$ & $6(21.42)$ & $14(18.91)$ & $54(22.5)$ & \\
\hline & Understanding and could explain to others & $34(24.63)$ & $7(25.0)$ & $10(13.51)$ & $51(21.25)$ & \\
\hline \multirow[t]{4}{*}{ Absolute risk } & It would not be helpful for me to understand & $30(21.73)$ & $3(10.71)$ & $22(29.72)$ & $55(22.91)$ & $0.035^{*}$ \\
\hline & Do not understand but would like to & $30(21.73)$ & $12(42.85)$ & $32(43.24)$ & $74(30.83)$ & \\
\hline & Some understanding & $44(31.88)$ & $2(7.14)$ & $10(13.51)$ & $56(23.33)$ & \\
\hline & Understanding and could explain to others & $34(24.63)$ & $11(39.28)$ & $10(13.51)$ & $55(22.91)$ & \\
\hline \multirow[t]{4}{*}{ Systematic reviews } & It would not be helpful for me to understand & $44(31.88)$ & $12(42.85)$ & $21(28.37)$ & $77(32.08)$ & $0.022^{*}$ \\
\hline & Do not understand but would like to & $44(31.88)$ & $6(21.42)$ & $11(14.86)$ & $61(25.41)$ & \\
\hline & Some understanding & $30(21.74)$ & $8(28.57)$ & $31(41.89)$ & $69(28.75)$ & \\
\hline & Understanding and could explain to others & $20(14.49)$ & $2(7.14)$ & $11(14.86)$ & $33(13.75)$ & \\
\hline \multirow[t]{4}{*}{ Odds ratio } & It would not be helpful for me to understand & $44(31.88)$ & $11(39.28)$ & $40(54.05)$ & $95(39.58)$ & $0.012^{*}$ \\
\hline & Do not understand but would like to & $54(39.13)$ & $6(21.42)$ & $12(16.21)$ & $72(30.0)$ & \\
\hline & Some understanding & $20(14.49)$ & $6(21.42)$ & $12(16.21)$ & $38(15.13)$ & \\
\hline & Understanding and could explain to others & $20(14.49)$ & $5(17.4)$ & $10(13.51)$ & $35(14.58)$ & \\
\hline \multirow[t]{4}{*}{ Meta-analysis } & It would not be helpful for me to understand & $32(23.18)$ & $9(32.14)$ & $16(21.62)$ & $57(20.83)$ & $0.036^{*}$ \\
\hline & Do not understand but would like to & $68(49.27)$ & $8(28.57)$ & $20(27.02)$ & $96(40.0)$ & \\
\hline & Some understanding & $20(14.49)$ & $6(21.42)$ & $24(32.43)$ & $50(20.83)$ & \\
\hline & Understanding and could explain to others & $18(13.04)$ & $5(17.4)$ & $14(18.91)$ & $37(15.41)$ & \\
\hline \multirow[t]{4}{*}{ Clinical effectiveness } & It would not be helpful for me to understand & $54(39.13)$ & $15(53.57)$ & $26(35.13)$ & $95(39.58)$ & $0.028^{*}$ \\
\hline & Do not understand but would like to & $54(39.13)$ & $6(21.42)$ & $17(22.97)$ & $77(32.08)$ & \\
\hline & Some understanding & $10(7.24)$ & $3(10.71)$ & $26(35.13)$ & $39(16.25$ & \\
\hline & Understanding and could explain to others & $20(14.49)$ & $4(14.28)$ & $5(6.75)$ & $29(12.08)$ & \\
\hline \multirow{4}{*}{$\begin{array}{l}\text { Number needed to } \\
\text { treat }\end{array}$} & It would not be helpful for me to understand & $24(17.39)$ & $5(17.4)$ & $26(35.13)$ & $55(22.91)$ & $0.044^{*}$ \\
\hline & Do not understand but would like to & $76(55.07)$ & $10(35.71)$ & $14(18.91)$ & $100(41.66)$ & \\
\hline & Some understanding & $15(10.86)$ & $7(25.0)$ & $24(32.43)$ & $46(19.16)$ & \\
\hline & Understanding and could explain to others & $23(16.66)$ & $6(21.42)$ & $20(27.02)$ & $49(20.41)$ & \\
\hline \multirow[t]{4}{*}{ Confidence Interval } & It would not be helpful for me to understand & $36(26.08)$ & $12(42.85)$ & $16((21.61)$ & $64(26.66)$ & $0.016^{*}$ \\
\hline & Do not understand but would like to & $64(46.37)$ & $6(21.42)$ & $27(36.48)$ & $97(40.41)$ & \\
\hline & Some understanding & $14(10.14)$ & $8(28.57)$ & $16(21.62)$ & $38(15.83)$ & \\
\hline & Understanding and could explain to others & $24(17.39)$ & $2(7.14)$ & $15(20.27)$ & $41(17.08)$ & \\
\hline \multirow[t]{4}{*}{ Heterogeneity } & It would not be helpful for me to understand & $28(20.2)$ & $6(21.42)$ & $36(48.64)$ & $70(29.16)$ & $0.029^{*}$ \\
\hline & Do not understand but would like to & $72(52.17)$ & $5(17.4)$ & $7(9.45)$ & $84(356.0)$ & \\
\hline & Some understanding & $13(9.42)$ & $10(53.71)$ & $26(35.13)$ & $49(20.41)$ & \\
\hline & Understanding and could explain to others & $24(17.39)$ & $7(25.0)$ & $5(6.75)$ & $36(15.0)$ & \\
\hline \multirow[t]{4}{*}{ Publication bias } & It would not be helpful for me to understand & $52(37.68)$ & $7(25.0)$ & $46(62.16)$ & $105(43.75)$ & $0.031^{*}$ \\
\hline & Do not understand but would like to & $48(34.78)$ & $10(35.71)$ & $7(9.45)$ & $65(27.08)$ & \\
\hline & Some understanding & $12(8.69)$ & $8(28.57)$ & $16(21.62)$ & $36(15.0)$ & \\
\hline & Understanding and could explain to others & $26(18.84)$ & $3(10.71)$ & $5(6.75)$ & $34(14.16)$ & \\
\hline
\end{tabular}

*Statistically significant at $p<0.05$ 
Table 4: Perceived major barriers to practicing evidence-based dentistry

\begin{tabular}{|c|c|c|c|c|c|c|}
\hline $\begin{array}{l}\text { Perceived major } \\
\text { barriers }\end{array}$ & & $\begin{array}{l}\text { Group I } \\
(n=138 ; \\
100 \%)\end{array}$ & $\begin{array}{l}\text { Group II } \\
(n=28 ; \\
100 \%)\end{array}$ & $\begin{array}{l}\text { Group III } \\
(n=74 ; \\
100 \%)\end{array}$ & $\begin{array}{l}\text { Total } \\
(n=240 ; \\
100 \%)\end{array}$ & $p$-value \\
\hline \multirow{2}{*}{$\begin{array}{l}\text { Lack of personal } \\
\text { time }\end{array}$} & Yes & $100(72.46)$ & $12(42.85)$ & $34(45.94)$ & $146(60.83)$ & \multirow[t]{2}{*}{$0.036^{*}$} \\
\hline & No & $38(27.53)$ & $16(42.10)$ & $40(54.05)$ & $94(39.16)$ & \\
\hline \multirow{5}{*}{$\begin{array}{l}\text { Context of } \\
\text { primary care }\end{array}$} & Personal and organizational inertia & $25(18.11)$ & $10(35.71)$ & $23(31.08)$ & $58(24.16)$ & \multirow[t]{5}{*}{$0.023^{*}$} \\
\hline & Moral in general dentistry & $25(18.11)$ & $7(25)$ & $23(31.08)$ & $55(22.91)$ & \\
\hline & Lack of investment and authority and trust & $24(17.39)$ & $4(16)$ & $7(9.45)$ & $35(14.58)$ & \\
\hline & Difficulties in involving whole practice & $26(18.84)$ & $2(7.14)$ & $16(21.62)$ & $44(18.33)$ & \\
\hline & No financial gain in EBP & $38(27.53)$ & $5(17.85)$ & $5(6.75)$ & $48(20)$ & \\
\hline \multirow{4}{*}{$\begin{array}{l}\text { The evidence } \\
\text { itself }\end{array}$} & Lack of hard evidence & $34(24.63)$ & $7(25)$ & $36(48.64)$ & $77(32.08)$ & \multirow[t]{4}{*}{$0.017^{*}$} \\
\hline & Evidence not related to context of general dentistry & $66(47.82)$ & $10(35.71)$ & $17(22.97)$ & $93(38.75)$ & \\
\hline & Too much evidence & $20(14.49)$ & $7(25)$ & $16(21.62)$ & $43(17.91)$ & \\
\hline & Availability and access to information & $18(13.04)$ & $4(14.28)$ & $5(6.75)$ & $27(11.25)$ & \\
\hline \multirow{4}{*}{$\begin{array}{l}\text { Attitudes of } \\
\text { patients }\end{array}$} & Patients expectation & $42(30.43)$ & $11(39.28)$ & $36(48.64)$ & $89(37.08)$ & \multirow[t]{4}{*}{$0.001^{*}$} \\
\hline & Ineffective treatment & $58(42.02)$ & $6(21.42)$ & $15(20.27)$ & $79(20.41)$ & \\
\hline & The need for lengthy discussion with patients & $30(21.73)$ & $6(21.42)$ & $7(9.45)$ & $43(17.91)$ & \\
\hline & An ignorant media & $8(5.79)$ & $5(17.85)$ & $16(21.62)$ & $29(12.08)$ & \\
\hline \multirow[t]{3}{*}{ Personal attitude } & Attitude of colleagues & $50(36.23)$ & $10(35.71)$ & $28(37.83)$ & $88(36.66)$ & \multirow[t]{3}{*}{$0.04^{*}$} \\
\hline & Lack of critical appraisal skills & $50(36.23)$ & $9(32.14)$ & $28(37.83)$ & $87(36.25)$ & \\
\hline & Evidence-based dentistry seen as a threat & $38(27.53)$ & $9(32.14)$ & $28(37.83)$ & $75(31.25)$ & \\
\hline
\end{tabular}

*Statistically significant at $p<0.05$

Table 5: Transitional views on moving from opinion based on EBP

\begin{tabular}{|c|c|c|c|c|c|c|}
\hline Transitional views & & $\begin{array}{l}\text { Group I } \\
(n=138 \\
100 \%)\end{array}$ & $\begin{array}{l}\text { Group II } \\
(n=28 \\
100 \%)\end{array}$ & $\begin{array}{l}\text { Group III } \\
(n=74 ; \\
100 \%)\end{array}$ & $\begin{array}{l}\text { Total } \\
(n=240 \\
100 \%)\end{array}$ & $p$-value \\
\hline \multirow{3}{*}{$\begin{array}{l}\text { Methods of moving } \\
\text { toward evidence-based } \\
\text { dentistry }\end{array}$} & Learning skills of evidence-based dentistry & $70(50.72)$ & $12(42.85)$ & $27(36.48)$ & $109(45.1)$ & $0.001^{*}$ \\
\hline & $\begin{array}{l}\text { Seeking and applying evidence-based } \\
\text { summaries }\end{array}$ & $30(21.73)$ & $9(32.14)$ & $29(39.18)$ & $68(28.33)$ & \\
\hline & Using EBP protocols and guidelines & $38(27.53)$ & $7(25.0)$ & $28(37.83)$ & $73(30.41)$ & \\
\hline
\end{tabular}

*Statistically significant at $p<0.05$

dentistry. Statistically significant difference was found among the three groups with regard to perceived major barriers to practicing evidence-based dentistry (Table 4).

A total of $50.72 \%$ of group I dentists believe that learning skills of evidence-based dentistry helps them to utilize evidence-based dentistry effectively, whereas $39.1 \%$ of group III dentists felt that seeking and applying evidence-based summaries are beneficial to their daily practice along with $37.8 \%$ of group III dentist who agreed that using EBP protocols and guidelines would help them move toward evidence-based dentistry from opinions (Table 5).

\section{DISCUSSION}

The main aim of evidence-based dentistry is to develop standardized intervention strategies for best treatment outcomes. Integration of evidence-based dentistry into dental practice is a herculean task, as dental professionals are little reluctant to do that. Assessing knowledge, attitude, and behavior of the dental professionals toward the same is of prime importance. In the Indian scenario, very few studies have been conducted by different authors like Pratap et al, ${ }^{12}$ and Gupta et $\mathrm{al}_{,}{ }^{14}$ on this subject from various parts of India, but there were no data exploring knowledge, attitude, and behavior of dental professionals from the western part of Rajasthan; hence, the present study was undertaken to assess knowledge, attitude, and practice of oral healthcare professionals toward evidencebased dentistry.

It was found that $74.63 \%$ of full-time academician and $70.27 \%$ of academician into dental practice were the members of research organization like research gate. This provides a platform for the dental professionals to exchange the scientific ideas which in turn boost EBP. Most of the dentists were residing in urban settings and majority of them were not having established internet connection at their workplaces, and this might be the probable reason for not utilizing evidence-based dentistry in their daily practice. A study done by Pratap et $\mathrm{al}^{12}$ has shown somewhat similar results where professionals believe that colleagues are the best source of information rather than anything else. 
In our study, it was found that $55.4 \%$ of academicians with clinical attachments were aware but did not use evidence-based dentistry, while many of the academicians were not at all aware of Cochrane Database of Systematic Reviews along with database about abstracts and systematic reviews. However, the present study results were contradictory to the study conducted by McColl et al ${ }^{13}$ where $46 \%$ of general practitioners were aware but did not use evidence-based dentistry while $60 \%$ doctors were not aware of Cochrane Database of Systematic Reviews along with database of abstracts and systematic reviews. This study is also in contradiction with the study by Pratap et $\mathrm{ll}^{12}$ in which most postgraduates students were unaware of evidence-based dentistry, as most of the time they were busy in revising the basic syllabus and doing preclinical work, but were interested in finding information on evidence-based dentistry.

Academicians with clinical attachments had some understanding about systematic review. The possible reason behind it might be that the word systematic review is self-explanatory. Academicians with clinical attachments also believed that odds ratio would not be helpful for them to understand evidence-based dentistry, while full-time academicians believed the same about the term clinical effectiveness. Most of the academicians with clinical attachments were not able to understand, but would like to know about technical terms used in evidence-based dentistry. Similar findings have been reported by Gupta et $\mathrm{al}_{1}{ }^{14}$ and the authors noted that most of the participants had some knowledge and understanding about common technical words like meta-analysis and systematic review, etc., and wanted to know more about technical words used in evidence-based dentistry.

Gupta et $\mathrm{a}^{14}$ concluded that lack of time was the most common perceived barrier to practicing evidence-based dentistry and a similar finding was found by Pratap et $\mathrm{al}_{1}{ }^{12}$ while contradictory finding was seen in the study carried out by Apparaju et $\mathrm{al}^{15}$ in which poor availability of resources and lack of time were the two major perceived barriers. However, in the current study, all the academicians felt that lack of personal time was the major barrier, whereas academicians with clinical attachments believed that lack of hard evidence and patients' expectation were also considered other perceived barriers to practicing evidence-based dentistry.

In our study, it was noted that $50.7 \%$ of full-time academicians believe that learning skills of evidence-based dentistry helps them to utilize evidence-based dentistry, whereas $39.1 \%$ felt that seeking and applying evidencebased summaries are beneficial to their daily practice along with $37.8 \%$ of academicians with clinical attachment who suggested the idea of using EBP protocols and guidelines in contrast to the study by Kumar et $\mathrm{al}^{11}$ in which $41.67 \%$ of academicians with clinical attachments and $79.37 \%$ of only academicians preferred to apply and seek evidence-based summaries to practice, whereas $60 \%$ of oral health practitioners suggested the idea of learning skills of evidence-based dentistry to promote EBP.

\section{Limitation of the Study}

The limitation of the study was that there are high chances that many of the participants might have overreported their knowledge, attitude, and practice score on evidence-based dentistry as bias occurs due to selfreporting. Moreover, generalizability of the study results is limited by the smaller sample size. Further multicentric or nationwide studies are warranted to explore dental professionals' knowledge, attitude, and behavior toward evidence-based dentistry.

\section{CONCLUSION}

In most of the studies, personal time was the major perceived barrier to practice evidence-based dentistry and this study is no exception. Majority of the oral health practitioners were not aware about the concept of evidence-based dentistry and its proper integration into day-to-day practice. It somewhere indicates lacunae in education in depth on evidence-based dentistry in dental colleges. Appropriate changes in the form of addition of evidence-based dentistry modules in the dental curriculum with some mock drills, workshops, or some practical examination would serve to be beneficial to develop and practice evidence-based dentistry among dental professionals.

\section{CLINICAL SIGNIFICANCE}

In today's fast-changing world, where patients ask for best possible dental treatment and assurance of prognosis, it becomes imperative for the dentist to reach up to the expectations of the patient and evidence-based dental practice would be the best tool for this. It aids in reaching best decision-making, improving clinical expertise, and thereby improving patient safety and clinically successful dental treatment.

\section{REFERENCES}

1. Choudhry NK, Fletcher RH, Soumerai SB. Systematic review: the relationship between clinical experience and quality of healthcare. Ann Intern Med 2005 Feb;142(4):260-273.

2. DeshmukhMA, DodamaniAS, Karibasappa GN, Prashanth VK, Khairnar MR, Naik RG. Evidence-based dentistry: an overview. UJMDS 2015 Jan-Mar;3(1):70-74.

3. Ashri N, Al-Amro H, Hamada L, Al-Tuwaijri S, El Metwally A. Dental and medical practitioners' awareness and attitude toward evidence based practice in Riyadh Saudi Arabia: a comparative study. Saudi J Dent Res 2014 Jul;5(2):109-116. 
4. Rabb-Waytowich D. You ask, we answer: evidence-based dentistry: part 1: an overview. J Can Dent Assoc 2009 Feb;75(1): 27-28.

5. Winning T, Needleman I, Rohlin M, Carrassi A, Chadwick B, Eaton K, Hardwick K, Ivancakova R, Jallaludin RL, Johnsen D, et al. Evidence based care and the curriculum. Eur J Dent Educ 2008 Feb;12(Suppl 1):48-63.

6. Hyanes B, Haynes GA. What does it take to put an ugly face through the heart of a beautiful hypothesis? Ann Intern Med 2009 Mar;150(3):JC3-2-JC3-3.

7. Goldstein GR. What is evidence based dentistry? Dent Clin North Am 2002 Jan;46(1):1-9.

8. Somaraj V, Shenoy RP, Panchmal GS, Jodalli P, Sonde L. Evidence based dental practice: a review. J Appl Dent Med Sci 2015 Oct-Dec;1(3):112-122.

9. Kishore M, Panat SR, Aggarwal A, Agarwal N, Upadhyay N, Alok A. Evidence based dental care: integrating clinical expertise with systematic research. J Clin Diagn Res 2014 Feb;8(2):259-262.

10. Richards D, Lawrence A. Evidence based dentistry. Br Dent J 1995 Oct;179(7):270-273.
11. Kumar J, Patthi B, Singla A, Gupta R, Prasad M, Dhama K. Knowledge and usage of evidence-based practice among dentists in Modinagar, India: a questionnaire-based study. J Indian Assoc Public Health Dent 2017 Apr-Jun;15(2): 170-176.

12. Pratap K, Padma TM, Sandhya MP, Kalyan VS, Anitha A, Bhargava AS. Knowledge and attitude toward evidence-based dentistry among postgraduate students of a dental college in South India. Indian J Health Sci 2014;7(2):88-91.

13. McColl A, Smith H, White P, Field J. General practitioners' perceptions of the route to evidence based medicine: a questionnaire survey. BMJ 1998 Jan;316(7128):361-365.

14. Gupta M, Bhambal A, Saxena S, Sharva V, Bansal V, Thakur B. Awareness, attitude and barriers towards evidence based dental practice amongst practicing dentists of Bhopal City. J Clin Diagn Res 2015 Aug;9(8):ZC49-ZC54.

15. Apparaju V, KaleS, Srivastava N, Goswami RD, Kondaveei R, Panthagada SV. Role of evidence based dentistry in day to day dental practice-perception of postgraduate dental students and clinical practitioners-KAP Study. Br J Med Med Res 2016 Jul;16(9):1-7. 